\title{
Black Male Grief Through the Lens of Racialization and Oppression: Effective Instruction for Graduate Clinical Programs
}

\author{
Allen E. Lipscomb ${ }^{1} \&$ Wendy Ashley ${ }^{1}$ \\ 1 Social Work Department, College of Social and Behavioral Sciences, California State University Northridge, \\ Northridge, USA \\ Correspondence: Allen E. Lipscomb, Psy.D, MSW, LCSW, Assistant Professor, Social Work Department, College of \\ Social and Behavioral Sciences, California State University Northridge, 18111 Nordhoff Street, Northridge, CA \\ 91330-8226, USA. Tel: 818-677-7630. \\ Received: April 5, 2018 \\ Accepted: April 25, $2018 \quad$ Online Published: May 6, 2018 \\ doi:10.5430/irhe.v3n2p51 \\ URL: https://doi.org/10.5430/irhe.v3n2p51
}

\begin{abstract}
Although Black males have experienced mental health challenges analogous to other marginalized populations, Black men dealing with loss and trauma have a greater risk of experiencing severe mental health challenges than their White counterparts due to racism, classism, economic inequalities and socio-political injustices in existence since slavery. Although slavery was legally abolished in the United States in 1865, the legacy of slavery continues via systemic oppression, historical trauma and race based economic inequality. Thus, Black males' lived experience is entrenched with elements of psychological, historical, interpersonal, and intrapsychic anguish. Black men experience grief from multiple avenues, including loss, trauma and the psychological impact of oppression. The authors explored the grief experiences of Racialized Black Men $(\mathrm{N}=77)$ to identify the needs and challenges of this vulnerable population. Utilizing a Critical Race Theory (CRT) lens, recommendations are provided to educate mental health therapists both in graduate programs and as practitioners in the field regarding anti-oppressive clinical practices. Finally, effective clinical intervention practices are explored, with specific strategies for White and non-White therapists when working with this unique and often underserved population in the United States.
\end{abstract}

Keywords: Black male, mental health, clinical education, grief, critical race theory, racialized

"Before we can begin to study the Negro intelligently, we must realize definitely that not is he affected by all the varying social forces that act on any nation at his stage of advancement, but that in addition to these there is reacting upon him the mighty power of a peculiar and unusual social environment which affects to some extent every other social force. In the second place we should seek to know and measure carefully all the forces and conditions that go to make up these different problems, to trace the historical development of these conditions, and discover as far as possible the probable trend of further development."

-The Study of the Negro Problems (1898) W.E.B. Du Bois

\section{Introduction}

Despite the universality of grief, variation exists in how it is experienced and expressed among racialized Black identified men (RBIM) in the United States (Lipscomb, 2016). Racialization involves the identification, perception, viewing, categorization or imposition of a racial context; for Black men, this translates into the simultaneous experience of their ethnicity and gender as substantially larger than their other identity factors. For RBIM, everything is viewed through the lens of dual marginalization. Thus, understanding the experiences of Black male grief necessitates awareness of socio-political oppression as a consistent factor. Although studies regarding grief and loss have helped identify stages of grief, loss and bereavement, empirical research has yet to examine these factors for RBIM. The lack of research with RBIM provides disparities in service provision and clinical efficacy with this underserved population. The authors utilized a qualitative phenomenological study to explore the unique grief reactions among RBIM in the United States in order to contribute to best practice and education guidelines for master's level mental health professionals. Further, this information supports advocacy and increased visibility 
regarding the historical cultural nuances that exist among this vulnerable population.

\subsection{Grief in Racialized Black Males}

Grief is largely recognized as a complex, multidimensional phenomenon that is influenced by a variety of external factors. Grieving is part of the normal process of responding to a loss and can be experienced mentally, physically, socially and/or emotionally. Walter and McCoy (2009) define grief as a normal and natural emotional reaction to loss or change of any kind that is neither pathological, abnormal, nor an indicator of a characterological disorder. Berzoff and Silverman (2004) describe grief as conflicting feelings caused by the end of or change in a familiar pattern of behavior. Conventional emotional reactions to grief may include anger, guilt, anxiety, sadness and despair (Walter \& McCoy, 2009). If a loss includes threat to one's life, alters one's life dramatically or creates experiences that overwhelm the capacity for coping, the emotional, psychological and physiological residue left over from heightened stress can be traumatic (APA, 2016; Herman, 2015). However, grief in marginalized groups is not limited to loss. Research indicates that exposure to racial discrimination and racism is linked to psychological and emotional grief (Carter, 2007; Pieterse, Todd, Neville \& Carter, 2012; Shavers et al., 2012). Thus, grief with RBIM is nuanced; while the emotional experience of grief is universal, the lived experience of grief is compounded by socio-political factors. This "normal" experience juxtaposed with the trauma of oppression creates a unique range of clinical manifestations with Black men.

\subsection{The Realities of Black Mental Health}

The statistics regarding mental health for Black Americans are alarming when compared to those of White Americans. According to the United States Department of Health and Human Services Office of Minority Health [US HHS] (2016), Black Americans are 20 percent more likely to report serious psychological distress than adult White Americans. Black Americans living below poverty are three times more likely to report serious psychological distress than those living above poverty. Black Americans are more likely to report feelings of sadness, hopelessness, and worthlessness than are their White counterparts. And while Black Americans are less likely than White Americans to die from suicide as teenagers, Black teenagers are more likely to attempt suicide than are White teenagers (8.3 percent v. 6.2 percent) (US HHS, 2016). Black Americans of all ages are more likely to be victims of serious violent crime than are Whites, making them more likely to meet the diagnostic criteria for post-traumatic stress disorder (PTSD).

Black males face even greater stressors and challenges due to historical trauma, systemic oppression, prejudice and economic disparities rooted in racism (Bowleg, et al, 2017; Harris, 1995; Lipscomb, 2016). Black males are disproportionately over-represented in the United States jails and prisons, and the unemployment rate for Black men is over twice the rate of White men of the same age (Bowleg, et al, 2017). They are disproportionately exposed to poverty, unstable housing, increased HIV risk, homicide, unintentional injuries, suicide, heart disease, and cancer (Bowleg, et al, 2017; Bowleg \& Raj, 2012; Centers for Disease Control and Prevention [CDC], 2015; Dunlap, Benoit \& Graves, 2013). The vulnerability of Black men based primarily on their racial characteristics puts this population at considerable risk for mental health crisis, disability or death.

Despite high levels of need and significant discrepancies in risk, Black men do not consistently seek or access mental health treatment. Black males are least likely to seek psychotherapy and counseling services to treat mental health related challenges (including but not limited to anxiety, clinical depression, post-traumatic stress disorder, marital conflicts and challenging familial dynamics) (Woodward, Taylor, \& Chatters, 2011). Black men are also often absent from research trials. Black males frequently express concern about stigma, psychological vulnerability, and help-seeking as "wrong", which impacts adaptive relational coping behaviors (Harris, 1995; Ward, 2013). While many Black men indicated that they were willing to seek out some form of help (Harris, 1995), numerous were apprehensive about seeking traditional psychological services for mental health issues. Due to this level of discomfort, Harris (1995) asserted the necessity for implementation of diverse strategies, creative counseling techniques and expanded roles of mental health professionals, arguing "a broader spectrum of counseling goals is required than has traditionally been promoted by counselors" (p. 244). Traditional mental health may be helpful in addressing traditional manifestations of mental health symptoms, however, RBIM present with racialized symptoms, experiences and perspectives. Thus, culturally relevant treatment for this population must include consideration for the intersectionality and complexity of the lived experiences of racialized Black men.

\subsection{Oppression and Racialization as a Practice Foundation}

The macro-historical context of racialization must inform direct micro-clinical practice with Black men. It is crucial that mental health professionals exiting graduate school programs recognize the impact of racialization on Black men. 
When looking at race, sociologists prefer to use the term racialization as opposed to race in order to emphasize that racial identification is comprised of categories which serve as social constructions that change in time, space and circumference, and are attributed with status quo (Smiley, 2016). Although the variances in definition may appear negligible, they translate into monumental differences in perspective. Race for Black men is a definitive component of identity while racialization is an ongoing lived experience. Further, racialization is a double edged sword; RBIM experience the pain of racialized exchanges both interpersonally and intrapsychically. Systemic and interpersonal racialization are defined by stereotypes, microaggressions and marginalization projected from others, while intrapsychic racialization is a lens that views all experiences as tinged with racial and gender implications.

In order to understand Black male racialization, the consequences of historic and systemic oppression must be examined and explored. Bowman (2015) indicated that among high risk Black [racialized] men, chronic role strains and related psychosocial problems do not just occur at a point in time, rather, they evolve out of interactions between past role experiences, immediate role barriers, and adaptive efforts. The results of oppression manifest as systemic disparities and dysfunctional behaviors for Black racialized males, with violence as a primary concern. A substantial element of Black male violence is the direct result of their position within American society that has been and continues to be characterized by societal oppression, internalized racism, violent social learning environments, sexism, male socialization, and economic exploitation (Carter \& Sant-Barket, 2015). The cycle of violence has origins in the history of marginalization experienced by Black males in American society. Many struggle with feelings of alienation from a society that projects an illusion of citizenship and equality, while simultaneously contributing to the destruction of Black male self-worth and infringement on the efficacious transition to manhood. Oppression and lack of equity contribute to internalized rage and powerlessness, which may manifest as aggression, violence, or other unconventional methods of empowerment. In populations where access to resources, capital and equity are futile, powerlessness may alter prescribed channels of status and recognition. Thus, reactions of violence in Black male culture is often an attempt to regain control, respect and status as social capitol, especially when other forms of social capital have been denied or are unavailable (Anderson, 2009). The external expression of violence and the internal emotions of anger, powerlessness, and frustration experienced by Black men associated with the constant subjugation of daily reminders of their unequal status function as a precursor to mental and physical health concerns.

While systemic oppression and a socio-political history of subordination are significant barriers to psychological well-being, consistent disparate experiences with privileged groups in which racial identification and membership are the source of oppression are additional contributors to anger, distress and violence. Racialized experiences refer to acts that exclude, marginalize, and/or disenfranchise people of color during interactions with White people. These are often experienced as microaggressions and include "subtle insults (verbal, nonverbal, and/or visual) directed toward people of color, often automatically or unconsciously" (Solorzano et al., 2000, p. 60). A key element to the challenge of racialized experiences is that they tend to go unnoticed by White people (Frankenberg, 1993; Hardiman, 2001; Helms, 1992; McIntosh, 1988; Tatum, 1997). Responding to this dynamic is an additional dilemma; self-silencing often results in internal tension, resentment and self-loathing while interpersonal confrontation can perpetuate stereotypes of aggression and violence. Although challenging for Black men in daily life, the racialized dissonance between Black men and the primarily White clinical and research worlds commands immediate attention.

\subsection{Preparation for Clinical Practice With Black Men}

Each year colleges and universities across the United States graduate masters level clinical psychologists, marriage and family therapists, professional clinical counselors and clinical social workers. Because oppression is an embedded reality in our country perpetuated both by individual acts and systemic policies, practices and laws, it is of the utmost importance that graduate programs in mental health related disciplines teach students about the psychological impact of oppression and racialization (Bell, 2000; Delgado \& Stefancic, 2001). Oppression, racism, historical trauma and ongoing socio-political inequities have a monumental impact on Black men, imbuing their lived experiences with the stain of depravity and insufficiency. Historically, Black men have been repetitively stereotyped as angry, hypermasculine criminals, savages and thugs, resulting in increased incarceration, police brutality and internalized inferiority (Smiley \& Facunle, 2016). Misconceptions and prejudices about Black male identity have pervaded media, public policy and research, influencing how Black men's lived experiences are represented in practice informed research.

However, teaching methods for this type of intersectional content are frequently not inclusive, presenting race related material through the lens of a dominant narrative. The identity of the faculty often subtly or significantly impacts both their lens and the curriculum. When instructors represent dominant social groups, lectures may inadvertently 
support dominant perspectives, while alternative perspectives and accounts may be silenced or minimized (University of Michigan, 2017). With only 3 percent of college faculty Black males or females ( $2 \%$ are Black males), this type of intersectionality discourse cannot be left only to instructors who are themselves racialized clinicians (National Center for Educational Statistics, 2015). Thus, White instructors are charged with engaging students in critical analysis of dominant narratives in theory, diversity and clinical practice. It is vital for White educators in graduate programs across the United States to explicitly introduce racism, racial privilege and White supremacy into clinical pedagogy, regardless of content or subject matter. White allies can be are extremely powerful in re-educating practitioners in racial privilege, ultimately contributing to the elimination of racial oppression and emotional, psychological, and spatial suppression (Brookfield, 1995).

\section{Theoretical Perspective}

Cultural competence is critical to effective practice with marginalized groups. However, the cultural competence framework has been consistently critiqued as lacking the specificity to attain any concrete learning or practice objectives (Abrams \& Moio, 2009; Ashley \& Paez, 2015; Schiele, 2007). Schiele (2007) argued that utilization of a cultural competence model downplays the legacy of racism, leaving mental health practitioners unprepared to deal with the interpersonal and systemic realities of racism and oppression. More concerning is the charge that a cultural competence paradigm in graduate education may unintentionally reinforce a color blind, race neutral perspective, teaching students to ignore or downplay racial differences. Critical Race Theory (CRT) directly confronts racial ambiguity, with a mission to analyze, deconstruct and transform the relationship between racism and power (Abrams \& Moio, 2009). CRT emerged in the mid- 1970's in the wake of the civil rights movement, with origins in the fields of anthropology, history, philosophy, political science and sociology (Abrams \& Moio, 2009; Crenshaw et al. 1995; Delgado \& Stefancic, 2001). One of the key notions of CRT is that racism is more than just unrelated secluded acts by individuals, but is core phenomenon to American society, entrenched in the cultural, legal, and psychological domains. For people of color, the intersectional experience of racism based on their marginalized identities is a core component of the theory. Further, CRT advocates the rewriting of dominant groups' history to include the narratives of minimized, silenced and excluded groups (Abrams \& Moio, 2009). Because these tenets acknowledge the lived experiences of racialized Black males, is vital to utilize this type of theoretical perspective when comprehending and deconstructing their culturally specific grief experiences.

\section{Methodology}

\subsection{Research Design, Sampling and Recruitment}

Snowball and Purposive sampling was used to recruit Racialized Black Identified Men (RBIM) (N=77) reporting a) experiencing at least one incident of racialization (being harassed, targeted, surveillance or assaulted based on ascribed racial identification) and b) a traumatic significant loss (sudden, unexpected, and/or violent death) of a loved one (parent(s), spouse/partner, sibling, relative, or close friend) as a result of death in the United States. There was a mean age of 33 with $\mathrm{SD}=10.98$. All the participants completed high school and a third obtained a degree from a higher education institution. $85 \%$ of the participants were currently employed and $50 \%$ reported being in a committed long-term intimate relationship.

Recruitment avenues included community agency providers, social media networking groups, and word-of-mouth. Utilizing a Critical Qualitative Research (CQR) approach (Merriam (2009) and a Critical Race Theory as an exploratory framework the following four inquiries were asked to all participants: 1) How do you respond to a significant loss in your life? 2) Who do you go to when you have experienced a significant loss? 3) What was your emotional response to the loss? and 4) How would someone close to you describe your reaction to a significant loss? The researchers reviewed the interview transcriptions to develop themes around (a) transcriptions for initial ideas/observations; (b) line-by-line coding; (c) focused coding through constant comparison; and (d) theme development (Bazeley, 2012). Qualitative results were then utilized to construct and identify themes among the 77 RBIM's transcripts. Rigor was achieved through moderately prolonged engagement, maintaining an audit trial, member checking and peer co-coding (Bazeley, 2012).

\section{Findings}

Findings yielded multiple themes regarding the grief experiences of RBIM. In response to how they responded to significant loss, $60 \%$ of participants indicated that they accepted the loss, while 33\% reported responding with sadness/despair and 7\% of participants stated that they experienced aggression following a significant loss (Table 1). In response to whom they went to when experiencing a significant loss, $40 \%$ of participants reported going to their parents for guidance, nurturing and social support, while $37 \%$ sought close friends. $29 \%$ reported finding support in a 
spouse/partner, while $25 \%$ indicated they went to their siblings. An astonishing $13 \%$ of participants reported that they had no one to go to following a loss (Table 2). Regarding how others view their response to loss, the majority of participants (60\%) indicated they cried, while 33\% noted that others did not see their emotional response because they engaged in social isolation or withdrawal from peers and family (Table 3). Analysis also revealed that RBIM felt the need to be self-contained, stoic and to retreat when experiencing loss. Over 50\% of participants reported this being a major barrier to addressing their mental health needs and seeking out mental health support in the community, identifying fears of being labeled as an "aggressive Black man".

Table 1. How racialized Black men respond to loss

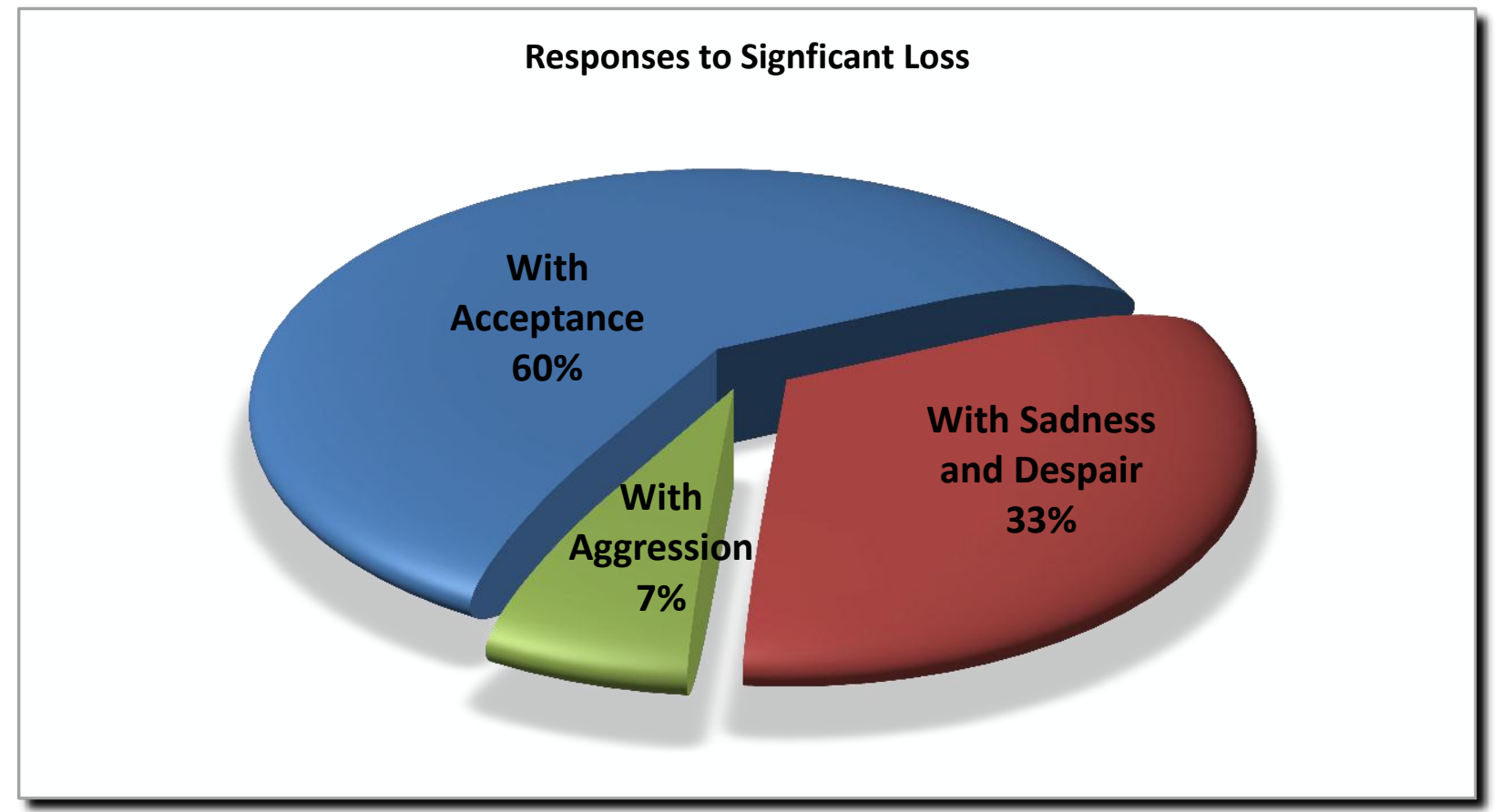

Table 2. Whom racialized Black men seek for support following loss

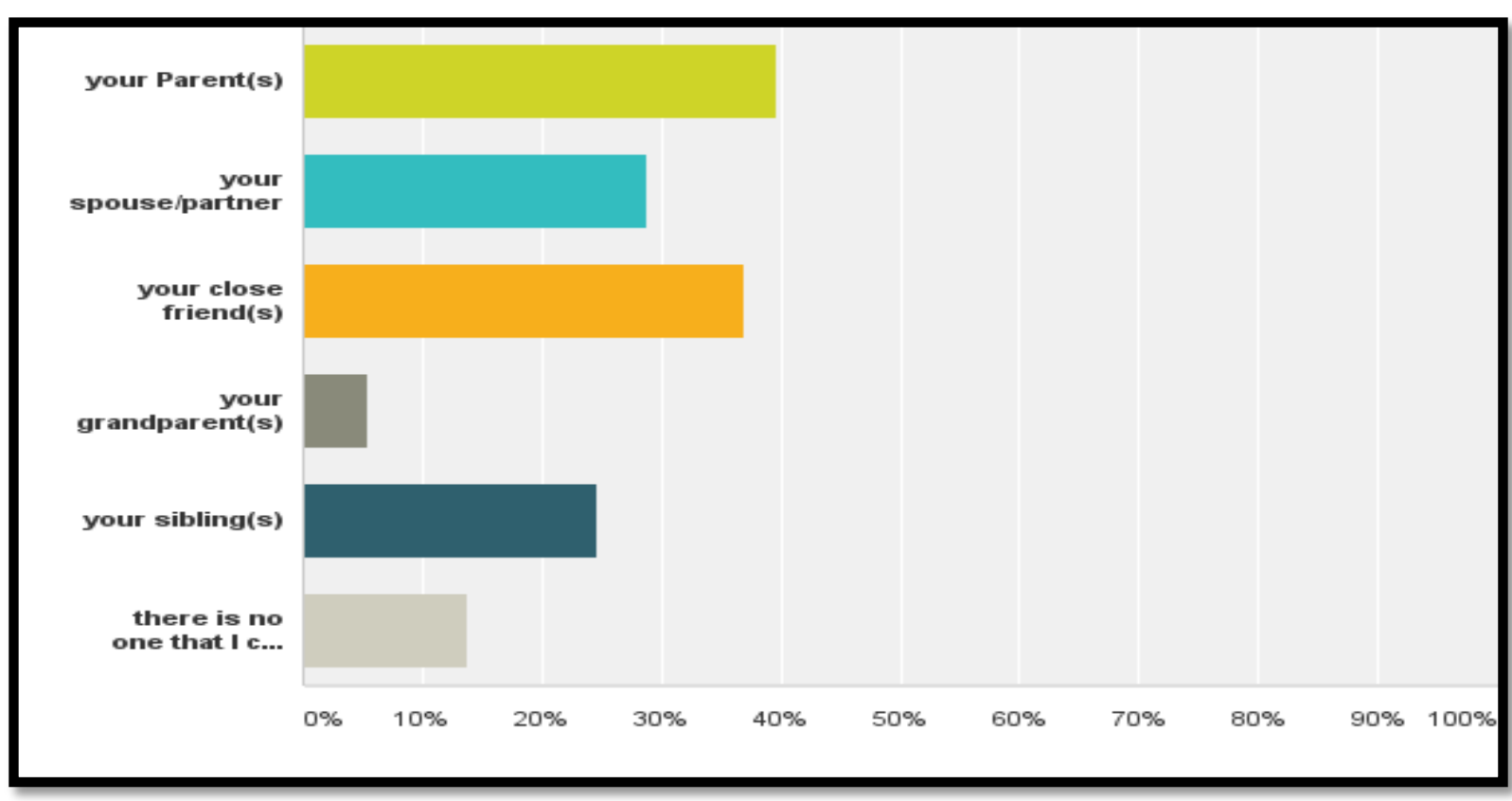


Table 3. Others view of racialized Black men's responses to loss

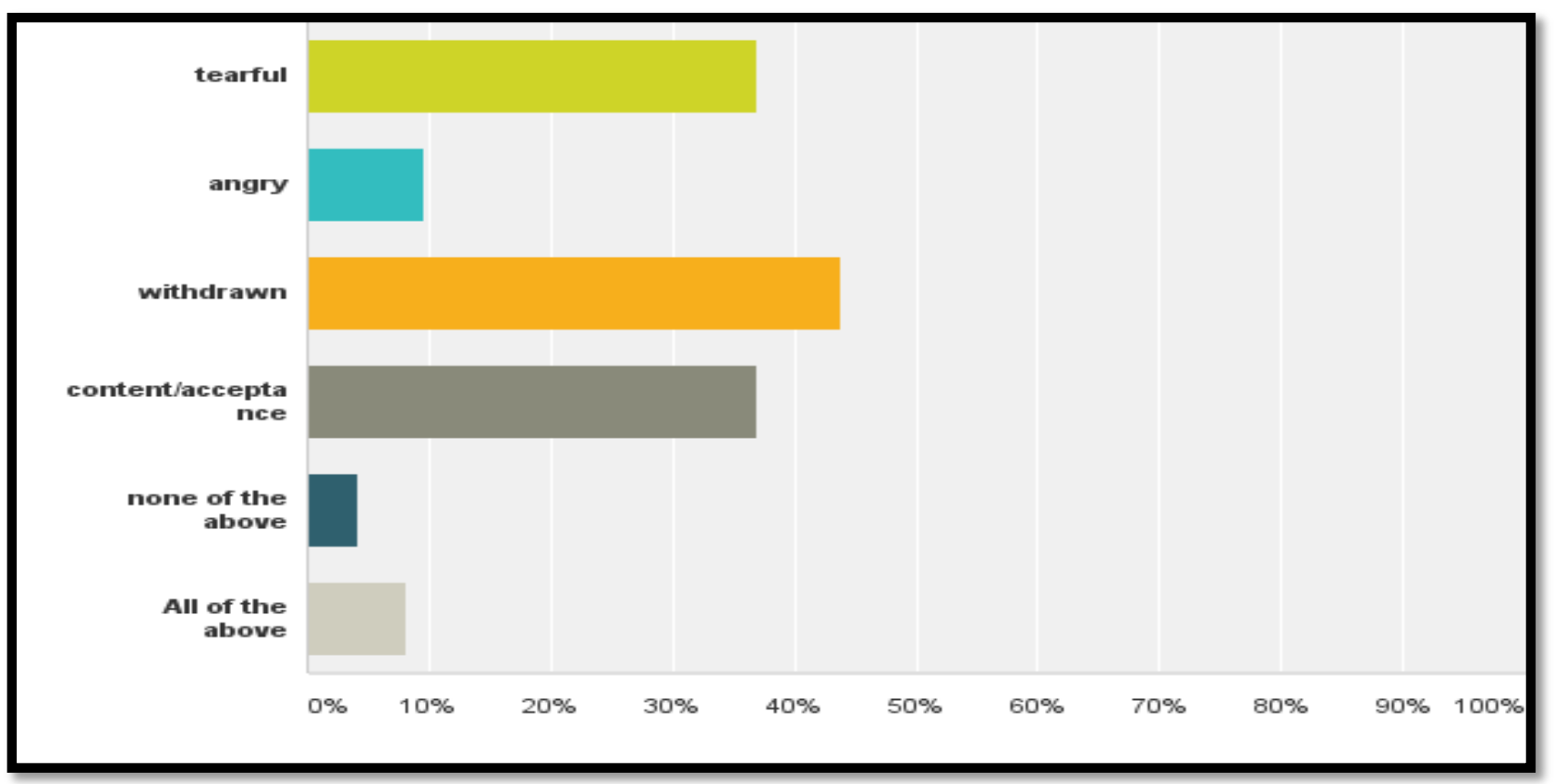

\section{Discussion}

The data suggest that despite lack of societal cognizance and individual challenges with verbalization of grief, RBIM have not been bereft of their racialized grief and loss experiences. More precisely, due to the complexity of internal, interpersonal and systemic factors, their grief can be described as disenfranchised grief and loss (Lathrop, 2017). The study demonstrated that grieving Black men both want and seek support; however, they primarily seek support from parents who are able to provide emotional support and lived experience validation and recognition. Critical to the findings is how RBIM frequently respond to a significant loss as though they have accepted the loss, however, this acceptance is likely to be predominantly a cognitive process. It is crucial to note that acceptance does not always mean one has grieved and mourned the loss. What the data illustrates is that despite their desire for acceptance, they are likely to be experiencing deeper emotional ambivalence and discomfort around the loss. Emotional ambivalence in RBIM bifurcates the sense of self, causing internal cognitive dissonance (Spencer, 2013). As a result, Black men not only experience physical losses but loss of their identity due to being racialized. The authors refer to this phenomena as forced cultural acceptance. Forced cultural acceptance is defined as the act of imposing a situation or condition onto another individual or group of people based on phenotypic presentation with dominance, power and force. This refers to cultural historical incidents in which Black men have been forced to accept and internalize emotionally charged experiences due to risk of being lynched, killed, beaten or tortured.

This information is critical for mental health professionals on many levels: prevention programs may include community outreach to families, offering services such as family groups; mental health first aid may be provided to family members; and mental health service providers can anticipate barriers for Black men experiencing significant loss regarding their willingness or comfort in expressing how they truly feel. Mental health professionals must also be taught to include parents in their treatment plans and encourage Black men to talk to someone whom they feel comfortable with (e.g. a parent; a friend; a companion, etc.). Participants in the study shared that treatment providers do not have to be a Black male to hold therapeutic space with them. In providing micro clinical services to Black men, clinicians must look for isolation and withdrawal, which may provide additional information of internal intrapsychic struggles. Further, ongoing assessment of suicidal thoughts, plans, means and attempts is a necessity. As previously mentioned, the internal experience of distress does not always translate to signs or symptoms, so mental health providers must be vigilant in continuous risk assessment. Larger implications from the research data reflect the clinical responsibility of mental health professionals (i.e. recent graduates and seasoned clinicians alike) to make therapy and counseling settings a safer space for Black men with objectives including: 1) Increased utilization of treatment services; 2) Allowing space and time for trust and emotional expression and 3) Patience with their individual processes. 
Qualitative data indicated that anger and aggression were responses to grief and loss for several participants, suggesting that aggression for Black males is consistently correlated with lack of acknowledgement or validation of their racialized grief experiences; particularly when they do not feel safe to emotionally express and grieve their experiences. Skills sets necessary for effective intervention include the following:

1) Speaking truth to experiences. Clinicians must avoid an adversarial position in therapy, to take a position of cultural humility, validating and recognizing racialized grief experiences as true and providing a genuine apology for microaggressive experiences (Lipscomb \& Ashley, 2017).

2) Normalizing feelings vs. pathologizing behaviors (i.e. stereotyping anger as aggression or threat). Instead, mental health professionals must normalize grief related anger, inquire about natural supports and encourage RBIM to use them. It is imperative to take the time to explore barriers to utilizing natural supports, as those challenges are consistently impediments to healing. Space must be provided in the therapeutic setting to allow dialogue regarding client comfort level with utilizing clinical space(s) for support and identifying barriers to vulnerability and safety.

3) Acknowledge experiences with power, privilege and oppression in clinical spaces. Grief experiences are rife with nuanced elements of loss, power, powerlessness and myriad other factors. Focus on "problems" or content related concerns without acknowledgement of power and privilege can create clinical barriers and challenges (i.e. stigma, stereotype, mis-labeling and displacing of emotions). Additionally, validation of power and privilege can strengthen the therapeutic relationship by acknowledging the depth of lived experience beyond content.

4) Joining in the space with them. Clinicians must tolerate their own discomfort in allowing RBIM to experience the emptiness of their loss and experience a true mourning process. The challenge for practitioners is in bearing witness to the loss, relationally sharing clinical space and allowing the RBIM to identify what grieving and healing and recovery looks like for themselves. The journey itself becomes a fundamental component of the process.

\section{Recommendations and Implications for Clinical Graduate Training Programs}

Findings suggest the importance of empirically-based training interventions around understanding and supporting grieving RBIM. In addition, further research is needed on identifying additional cultural and historical barriers that may impede treatment for this vulnerable population. Culturally relevant continuing education should be offered and implemented at all universities and colleges with mental health related programs. These learning opportunities should be provided to graduate students and future clinicians planning to work with RBIM in clinical or community mental health settings. Further, research should engage treatment providers who work this population in the community on identifying their perceived barriers, challenges and successes to providing anti-oppressive treatments for this population. Anecdotally effective interventions must be researched and explored with an ultimate goal of developing effective therapist-client relationships that promote and utilize core skills such as empathy, genuineness, unconditional positive regard, and consistency in how the therapist "shows up" for their Black male client. The ability of a therapist to accurately display empathy and understanding towards their Black male clients is a vital principle for gaining true rapport, buy-in and trust. Graduate training programs retain a responsibility to increase awareness regarding what the authors refer to as a cultural-relational dichotomy, consisting of inter-cultural comfort (clients of a different culture/racial group than the therapist avoid telling the therapist how they truly feel in order to ensure the therapist feels comfortable and safe while meeting with them) and intra-cultural congruence (clients of the same culture/racial group as the therapist share experiences in an effort to receive validation and affirmation around their racialized experiences). This dichotomy places focus on the client's perspective of and positionality with the therapist, constructing a barrier to establishing authentic, healing relationships.

Adopting and actively utilizing a CRT theoretical lens is essential when working with this marginalized group of men. CRT's multidimensional framework can aid in highlighting and identifying the connection between mental health and race. For example, a clinician's ability to recognize how systemic perpetuation of discrimination, racism and oppression adversely impacts the psychological health of Black men will directly influence the language and engagement skills they use to begin to develop rapport with RBIM (Carter, 2007; Carter \& Sant-Barket, 2015, Mcdowell, 2004). When therapist are educated and trained to properly utilize CRT they are more apt to recognize and understand the complexities and nature of the historical socio-political, economic and systemic oppression experienced by Black males in the United States. Comprehensive CRT instruction must be actively integrated in both academic and field practicum training to be effective in developing the knowledge, values and skills essential to work with disenfranchised groups. A well-developed CRT lens allows clinicians to be proactive in managing intersectionality and various psycho-social stressors when they are holding clinical-therapeutic spaces with grieving 
RBIM.

The provision of culturally reflexive services is of the utmost importance. With a CRT lens, White therapists are encouraged to not only be aware of the privileges they hold but also to acknowledge them in the therapeutic environment. Therapists will not know initially if the challenges presented by RBIM are unique to them as individuals or woven within a society that is oppressive by design, however, direct inquiry, time and space will provide increased clarity. Clinical academic training programs must infuse education around enhancing understanding of the intersecting and traumatic effects of prejudice, discrimination, and stereotyping and teach concrete methods of identifying strategies and interventions for addressing these unique challenges. Because the realities of oppression are always present for RBIM, it is the therapists' responsibility to be cognizant of their psychic reward (Better, 2008) and not avoid, minimize or project personal values, ideologies, and biases onto their clients. The lack of intersectional education, understanding, knowledge, and compassion causes additional emotional labor for RBIM, resulting in considerable disadvantage to both the client and the therapeutic relationship.

\section{Conclusion}

While grief is a universal emotion, it becomes more nuanced when viewed through the lens of the racialized Black male. Thus, treatment with this population is infinitely more complex than treating the grief or racialized trauma alone. Effective intervention requires an intersectional, Critical Race Theory lens to deconstruct current experience, past cultural-specific traumas, institutional/systemic traumas, and intergenerational traumas.

The significance of this research challenges and disrupts what we as society, cultural educators and mental health professionals have been ignoring - the unique RBIM grief experiences. The literature and mental health field is replete with information appraising a Eurocentric, academic dominant lens regarding what "should" occur when working with diverse individuals in the absence of seeking and honoring the voices of whom the profession is striving to serve. This research urges clinical practitioners and educators alike to be critically conscious and culturally reflexive when engaging, assessing and treating RBIM grief. The findings encourage a paradigm shift for graduate clinical training programs. Acknowledgement of unique intersectional identity experiences and the incorporation of CRT strategies in curriculum can target and remediate clinical pathologizing of behaviors and symptoms that are not understood. Academicians and clinicians must strive to challenge their mindset and recognize that to be anti-oppressive educators and clinicians, we must evolve our pedagogical approach and theoretical framework to make room for the lived experiences of vulnerable groups.

Finally, because of the limited research on the needs of RBIM by non-dominant researchers, there is a need for further research on addressing clinical issues and trauma specific treatments for Black men by researchers with multi-layered intersectional identities. Deconstruction of current lived experiences, historical and intergenerational trauma, and ongoing marginalization and oppression are critical to understand and engage in effective practice with this population. There is much information to be gained for the growth of instructors, students, mental health providers, researchers and scholars in providing comprehensive, culturally relevant mental health services to RBIM.

"Death is not the greatest loss in life. The greatest loss is what dies inside while still alive. Never surrender." -Tupac Shakur

\section{References}

Abrams, L., \& Moio, J. (2009). Critical race theory and the cultural competence dilemma in social work education. Journal of Social Work Education, 45(2), 245-261. https://doi.org/10.5175/JSWE.2009.200700109

American Psychological Association. (2016). African Americans have limited access to mental and behavioral health care. Retrieved from http://www.apa.org/about/gr/issues/minority/access.aspx

Anderson, V. (2009). Lopsided discipline takes toll on black male students. (Editorial). Catalyst Chicago, 2.

Ashley, W., \& Paez, J. (2015). Enhancing strengths based pedagogy: From cultural competence to Critical Race Theory. The International Journal of Interdisciplinary Educational Studies, 10(4), 15-25.

Bazeley, P. (2012). Regulating Qualitative Coding Using QDAS?. Sociological Methodology, 42(1), 77-78. https://doi.org/10.1177/0081175012460852

Bell, D. A., Jr. (2000). Property rights in whiteness: Their legal legacy, their economic costs. In R. Delgado \& J. Stefancic (Eds.), Critical race theory: The cutting edge (2nd ed., pp. 71-79). Philadelphia: Temple University 
Press.

Berzoff, J., \& Silverman, P. (Eds.). (2004). Living with dying: A handbook for end-of-life healthcare practitioners. New York: Columbia University Press.

Better, S. (2008). Institutional Racism: A Primer on Theory and Strategies for Social Change (2nd ed.). Chicago: Burnham.

Bowleg, L., \& Raj, A. (2012). Shared communities, structural contexts, and HIV risk: Prioritizing the HIV risk and prevention needs of black heterosexual men. The American Journal of Public Health, 102(5), S173. https://doi.org/10.2105/AJPH.2011.300342

Bowleg, L., Del Río-González, A., Holt, S., Pérez, C., Massie, J., Mandell, J., \& A. Boone, C. (2017). Intersectional Epistemologies of Ignorance: How Behavioral and Social Science Research Shapes What We Know, Think We Know, and Don’t Know About U.S. Black Men's Sexualities. The Journal of Sex Research, 54(4-5), 577-603. https://doi.org/10.1080/00224499.2017.1295300

Bowman, M. (2015). Completing an incomplete history: The African American narrative in civil war Helena. Race, Gender \& Class, 22(1/2), 236-247.

Brookfield, S. D. (1995). Becoming a Critically Reflective Teacher. San Francisco: Jossey-Bass.

Carter, R. T. (2007). Racism and psychological and emotional injury: Recognizing and assessing race-based traumatic stress. The Counseling Psychologist, 35, 13-105. https://doi.org/10.1177/0011000006292033

Carter, R. T., \& Sant-Barket, S. M. (2015). Assessment of the impact of racial discrimination and racism: How to use the Race-Based Traumatic Stress Symptom Scale in practice. Traumatology, 21, 32-39. https://doi.org/10.1037/trm0000018

Centers for Disease Control (CDC). (2015). Fact Sheet. Atlanta, GA: CDC.

Crenshaw, K., Gotanda, N., Peller, G., \& Thomas, K. (Eds.). (1995). Critical race theory: The key writings that formed the movement. New York: The New Press.

Delgado, R., \& Stefancic, J. (2001). Critical Race Theory: An Introduction. New York: New York University Press.

Du Bois, W. E. B. (1898). The Study of the Negro Problems. Annals of the American Academy of Political and Social Science, 568, 13-298. https://doi.org/10.1177/000271620056800103

Dunlap, E., Benoit, E., \& Graves, J. L. (2013). Recollections of Sexual Socialisation among Marginalised Heterosexual Black Men. Sex Education: Sexuality, Society and Learning, 13(5), 560-572. https://doi.org/10.1080/14681811.2013.776956

Frankenberg, R. (1993). White women, race matters: The social construction of whiteness. Minneapolis: University of Minnesota Press.

Hardiman, R. (2001). Reflections on white identity development theory. In C. L. Wijeysenghe \& B. W. Jackson, III (Eds.), New perspectives on racial identity development: A theoretical and practical anthology (pp. 108-128). New York: New York University Press.

Harris, S. (1995). Psychosocial development and Black male masculinity: Implications for counseling economically disadvantaged African American male adolescents. Journal of Counseling and Development, 73(3), $279-287$. https://doi.org/10.1002/j.1556-6676.1995.tb01749.x

Helms, J. E. (1992). A race is a nice thing to have: A guide to being a white person or understanding the white person in your life. Topeka, Kansas: Content Communications.

Herman, J. L. (2015). Trauma and Recovery: The Aftermath of Violence--From Domestic Abuse to Political Terror. New York: Basic Books.

Lathrop, D. (2017). Disenfranchised Grief and Physician Burnout. Annals Of Family Medicine, 15(4), $375-378$. https://doi.org/10.1370/afm.2074

Lipscomb, A. E. (2016). Black Male Grief Reaction to Trauma: A Clinical Case Study of One Man's Mental Health Treatment. CreateSpace Publications.

Lipscomb, A. E., \& Ashley, W. (2017). Colorful Disclosures: Identifying Identity-Based Differences and Enhancing Critical Consciousness in Supervision. Smith College Studies in Social Work. https://doi.org/10.1080/00377317.2017.1324098 
Mcdowell, T. (2004). Exploring the Racial Experience of Therapists in Training: A Critical Race Theory Perspective. The American Journal of Family Therapy, 32(4), 305-324. https://doi.org/10.1080/01926180490454791

McIntosh, P. (1988). White privilege and male privilege: A personal account of coming to see correspondences through work in women's studies. Wellesley College: Center for Research on Women, 189.

Merriam. S. B. (2009). Qualitative research: A guide to design and implementation (4th ed.). San Francisco, CA: Jossey-Bass.

National Center for Educational Statistics. (2015). Percentage distribution of full time faculty in degree granting postsecondary institutions, by academic rank, race/ethnicity, and sex. Fall, 2015. Retrieved from https://nces.ed.gov/fastfacts/display.asp?id=61

Pieterse, A. L., Todd, N. R., Neville, H. A., \& Carter, R. T. (2012). Perceived racism and mental health among Black American adults: A meta-analytic review. Journal of Counseling Psychology, 59, 1-9. https://doi.org/10.1037/a0026208

Schiele, J. H. (2007). Implications of the equality-of-oppressions paradigm for curriculim content on people of color. Journal of Social Work Education, 43, 83-100. https://doi.org/10.5175/JSWE.2007.200400478

Shakur, T. (1997). Tupac Shakur in His Own Words MTV News. Archived from the original on January 4, 2016 [Tupac pronounces his own name at 2:29.]

Shavers, V. L., Fagan, P., Jones, D., Klein, W. M., Boyington, J., Moten, C., \& Rorie, E. (2012). The state of research on racial/ethnic discrimination in the receipt of health care. American Journal of Public Health, 102, 953-966. https://doi.org/10.2105/AJPH.2012.300773

Smiley, C., \& Facunle, D. (2016). From "brute" to "thug:" The demonization and criminalization of unarmed Black male victims in America. Journal of Human Behavior in the Social Environment, 26(3-4), 350-366. https://doi.org/10.1080/10911359.2015.1129256

Solorzano, D., Ceja, M., \& Yosso, T. J. (2000). Critical race theory, racial microaggressions, and campus racial climate: The experiences of African American college students. Journal of Negro Education, 69(1/2), 60-73.

Spencer, M. B. (2013). Cultural cognition and social cognition as identity correlates of Black children's personal-social development. Beginnings: The Art and Science of Planning Psychotherapy, 215.

Tatum, B. D. (1997). Why are all the black kids sitting together in the cafeteria? And other conversations about race. New York: Basic Books.

U.S. Department of Health and Human Services Office of Minority Mental Health. (2016). Mental health and African Americans. Retrieved from http://minorityhealth.hhs.gov/omh/browse.aspx?lvl=4\&lvlid=24

University of Michigan (2017, August 24). Inclusive Teaching: Dominant Narratives. College of Literature, Science and the Arts. Retrieved from sites.lsa.umich.edu

Walter, C., \& McCoyd, J. (2009). Grief and loss across the lifespan: A biopsychosocial perspective. New York: Springer Publishing Company.

Ward, E. C., Wiltshire, J. C., Detry, M. A., \& Brown, R. L. (2013). African American men and women's attitude toward mental illness, perceptions of stigma, and preferred coping behaviors. Nursing Research, 62(3), 185-194. https://doi.org/10.1097/NNR.0b013e31827bf533

Woodward, A., Taylor, R., Bullard, K., Aranda, M., Lincoln, K., \& Chatters, L. (2012). Prevalence of lifetime DSM-IV affective disorders among older African Americans, Black Caribbeans, Latinos, Asians and Non-Hispanic White people. International Journal of Geriatric Psychiatry, 27(8), 816-827. https://doi.org/10.1002/gps.2790 